\title{
The Importance of Quality and Product Design in the New Textile Production Markets
}

\author{
Paula Nogueira ${ }^{1}$, Sónia Oliveira ${ }^{2}$, Maria João Felix ${ }^{3}$ and Gilberto Santos ${ }^{3 *}$ \\ ${ }^{1}$ Institute of Interdisciplinary Research, Coimbra University, Portugal \\ ${ }^{2}$ Technology School-Polytechnic Institute Cávado Ave, Portugal \\ ${ }^{3}$ Design School ESD-Polytechnic Institute Cávado Ave, Portugal \\ *Corresponding author: Gilberto Santos, Design School (ESD- Polytechnic Institute Cávado Ave, Portugal
}

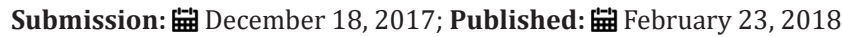

\begin{abstract}
The textile industry has a long tradition in Portugal and is one of its most important sectors. The relocation of production to emerging countries - India, Pakistan and China where manufacturing costs are significantly lower (e.g. labour costs, taxes and transport costs) and governments grant subsidies brings unemployment to countries that previously produced for major international brands. If, on the one hand, in Portugal there are companies where it is possible to make textile production, on the other hand, Portugal has a lack of design of products and own brands. When large brands relocate production, unemployment increases in countries where large brands previously made their production. But there is another big problem. In emerging countries the product quality is low and many times, they do not respect intellectual property.

The objective of this work was to determine the importance of quality in the portuguese textile firms, as well as, the problem that exists regarding the lack of design of own products. Data from 60 textile firms were examined. One the main reason for clients to seek other markets is price. Other important conclusion is that the majority of the firms stated that the implementation of quality programs led to higher profits and an improvement in the quality of their output. Overall, the implantation of a quality program has improved their competitive position and their overall performance.
\end{abstract}

Keywords: Portuguese textile industry; Quality management system; Intellectual property; Product design

\section{Introduction}

The rapid development of technology and communications has reduced the distance between nations and improved the time from order to delivery [1]. Hence, today's economy is global [2]. As with Portugal, according to Towers [3] many textile businesses have significantly reduced their manufacturing capacity in the UK and have transferred some or all of it overseas to Eastern Europe, the African continent and Asia. With their significantly lower labour and production costs, such companies are able to widen their profit margins considerably. Hence, according Middleton [4], the textiles market has become highly competitive, with the main manufacturing base moving from the developed countries to the developing countries such as India, Pakistan and China, where manufacturing costs are significantly lower (e.g. labour costs, taxes and transport costs) and governments grant subsidies. The lower production costs allow developing countries to export goods at cheaper prices than developed countries, which are compounded when developing countries markets mature and they have difficulty selling the goods. When large brands relocate production, unemployment increases in countries where large brands previously made their production [5]. A major problem is developing countries do not have design of their own products, and also, they do not have their own universal brands [6].
But there is another big problem. In emerging countries the product quality is low and many times, they do not respect intellectual property [7]. In Portuguese companies the quality is excellent [8], but the biggest problem of the Portuguese textile industry is the lack of product design, which is usually done in the headquarters of large international companies, that is, in the developed countries, namely G7 countries [7].

This lack of product design is due to the fact that design was introduced extremely late in Portugal. This delay made it difficult to create a design history in Portugal, which is also related to the late autonomy of university studies in design as well different productive and institutional realities.

As is common with all European design culture, the first phase of Design's affirmation was in the nineteenth century with Decorative Arts and in Portugal, this period was particularly prolonged and included the first half of the 20th century due to the late start of industry and to the dictatorship regime, which contributed to the delay of the whole process of recognition of the area. Only in the 50 's can we see the design begin to develop, in its methodological configuration, with the leading role of the industry. It was at that time that Portugal began to have a clearer perception of the role of 
designers and design in society, generalized to a variety of sectors like industry, design and institutions.

The lack of historical tradition of the design profession in Portuguese society has limited the development of industrially standardized products and poorly oriented in terms of production [9].The result was increasing interference from different areas of knowledge, which disconnected from the design theme and the "industrial" process, sometimes led to inconsistent production solutions. Thus, the result is a product that can be characterized by a successive search for an approach to a hybrid language between art and product, where several methodologies and work areas are analyzed and crossed. All of this contributed to the complex integration of design and industry in Portugal.

In order for companies in developed countries to remain in business, they must change their strategy drastically [4]. As such evaluation of product quality is a complex task in which a hierarchy of attributes needs to be taken into account [10]. Within this concept, according to Towers [3], Total Quality Management (TQM) is an approach to improving the competitiveness and flexibility of an organisation for the benefit of all stakeholders. It is a way of planning, organising and understanding each activity and of removing all the wasted effort and energy that is routinely exerted in the organisation. It ensures the leaders within the organisation adopt a strategic overview of quality and focus on the prevention of problems [3]. Quality, or more importantly perceived customer value, is an important source of competitive advantage for a modern company [4]. On other hand, with today's global competitive marketplace, new textile product development requires a design, marketing, materials and technology interface [11]. For such requirements it is also necessary behavioural guidelines that all technicians must adopt independently of the technology to which they engage [12] but some of them are especially important to apply on mechanics and materials selection in design.

The textile industry has a long tradition in Portugal and is still one of its most important industrial sectors. It has always assumed a prominent role in terms of employment and thus a relevant position within the Portuguese economy. Furthermore, it has registered dynamic and competitive behaviours in certain sub-sectors and firms. The geographical and cultural proximity to the European market is a positive aspect, which firms must take advantage of [13]. Although it is a mature sector, it is quite fragmented and subject to periodic mismatches between supply and demand. Thus its performance is strongly conditioned by fluctuations in the global economic activity. Nonetheless, the Portuguese textile industry has revealed to be dynamic in many sectors, such as clothes making, although it has been losing its market share in favour of European Union countries, in particular those with cheaper labour [13]. The global textile trade liberalization and the consolidation of the position of Asian countries in the European market have increased the difficulties that this sector has experienced in the last years, affecting not only Portugal but the entire European textile industrial sector [14]. Most countries have lost clientele due to the lack of quality and the practice of lower prices by competing countries. On the other hand, by focusing their operations on quality and speed of response as well as cost, UK based organisations have been able to sustain a position in their markets [3]. Also in Portugal, quality became an important survival factor for the textile sector. This is an attribute generally sought out by potential clients. In addition, clients search for partners that they can delegate responsibility to. This typically does not occur with Asian firms, contrary to the case with Portuguese firms.

The needs and demands of the present markets, which are becoming increasingly global and competitive, have made the improvement of quality into a maxim to be followed by organizations who wish to consolidate their market position [15]. The concern for increasing competitiveness has favoured the development of Quality Management in large and small companies. According to Rebelo et al. [16], the sustained success of an organization is achieved by its ability to satisfy the needs and expectations of its customers and other stakeholders in the long run and in a balanced way. Presently, in the context of a global market that is becoming progressively more demanding and competitive, organizations are under substantial pressure to meet the requirements of their stakeholders.

The subject of organizational culture is becoming more and more important for organizations in the pursuit of quality and excellence [17] because evaluation of product quality is a complex task in which a hierarchy of attributes needs to be taken into account. More research attention should be paid to the core values related to building a quality culture, such as customer-centrism (focus on customers' problems, needs, and expectations), continuous improvement, and the participation of everyone involved [17]. Within this context, the Quality Management System (QMS) is an important tool to increase competitiveness and increase a firm's market share. As part of a TQM approach, an organisation must develop and implement an appropriate quality assurance system that is tailored to the type of manufacturing activity for the product or service being offered. A fully documented Quality Management System (QMS) will ensure that the two important requirements of customer expectation and the organisation's requirements, both internally and externally, are met [3].

When QMS is well implemented, it is an instrument that can manage everything in a firm such as human resources, behaviours, involving everybody in the firm, with the clients and the society. Workers are an important link in the firm's performance and if all involved perform their functions properly, this will be reflected throughout the firm. Quality improvement has been an important part of competitive strategies of firms. In this context, TQM has emerged as a business management strategy which aims to create awareness of quality through all organizational processes. The TQM philosophy has resulted in a tremendous interest in, and efforts to develop, good practices [18]. Worldwide, the quest for quality is an endeavour that organizations in every industry embark on in a continuous effort to succeed. The main objective is for organizations to reach world-class excellence through high-quality products and/or services, customer satisfaction, and cost reduction 
with profit optimization. It was found that the issues that influence quality performance, cost performance and sales performance of ISO 9000 vary according to company size; however, issues defining the performance of internationalization are the same for small, medium and large companies [19]. Firms are normally encouraged by the market to become certified, but above all, as a requirement by major clients. The quality system certification improves business relations and it has a positive effect on a financial perspective [20]. Studies suggests that the ISO 9001 system can be a useful tool for organizational learning and knowledge management, and can usefully complement knowledge management approaches in that sense. To do so, managers must have a broad, and sometimes, a critical interpretation of the ISO 9001 standard. This will not only comply with the requirements of the certifying body, but also achieve internal efficiency in the organization [21].

The objective of this work was to determine the importance of quality in the Portuguese textile firms, as well as, the problem that exists regarding the lack of design of own products.

\section{Methods}

\section{Data from the questionnaire}

To undertake our analysis, we made use of a questionnaire with the many questions presented in Table 1 .

Table 1: Main sections and main topics included the original survey [7].

\begin{tabular}{|c|c|}
\hline Main Sections & Main Topics \\
\hline General description of the firm & $\begin{array}{c}\text { Type; Firm's Activity; Year of first } \\
\text { certification; Number of employees; }\end{array}$ \\
\hline Motivations \\
Benefits \\
Deployment time \\
Payback \\
Practices used before \\
Beployment of the quality \\
management system - ISO 9000 \\
certification \\
Competition \\
Deployment level \\
Factors \\
Income \\
Income of the QMS \\
Impact \\
Archetype \\
Income obtained from the QMS \\
Culture
\end{tabular}

The study presents the benefits, drawbacks and difficulties of implementing quality management systems and the importance of quality in the production process. The questionnaire was sent to 260 firms. However, the sample for our study was of 60 firms in total that is about $23 \%$ of respondents.

\section{Data Collection}

The questionnaire used simple and clear language. We also sent the firms additional questions to obtain more information about the current situation in the textile industry in Portugal. These questions covered topics, such as, the importance of quality in the textile firms in Portugal, the actual situation of the textile sector, the reasons why some clients are searching new markets and leaving Portugal. While issues related to the importance of the quality system have already been analyzed [7], issues related to the new textile production markets will be discussed in more detail in this paper.

\section{Results}

\section{Results from questionnaire}

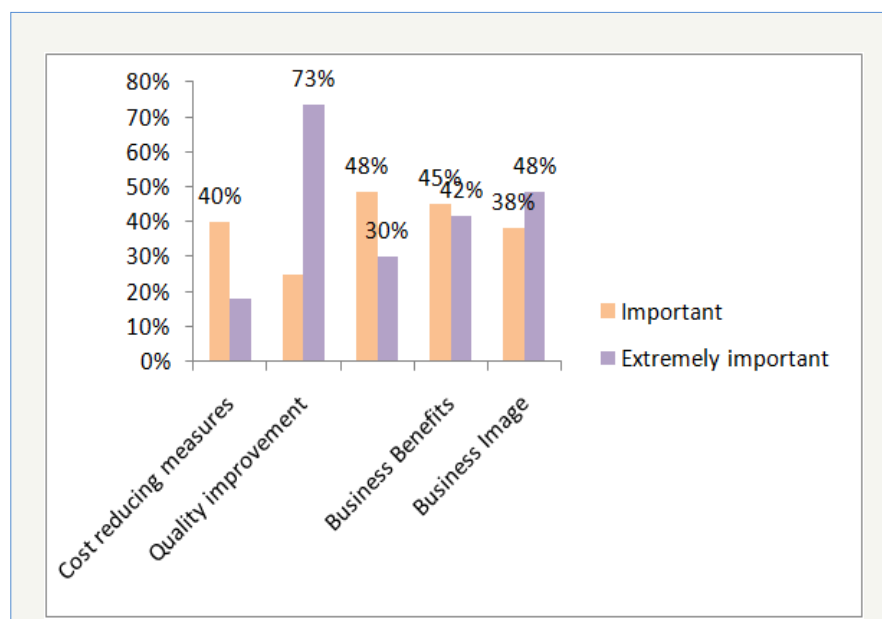

Figure 1: Reasons to implement quality system according ISO 9001 (adapted from Oliveira [7]).

All firms included in our sample were Portuguese with the exception of one. According to Figure 1, most firms in our sample felt that quality improvement, business benefits, mobilizing employees' knowledge and business image were important or extremely important factors to implement certification.

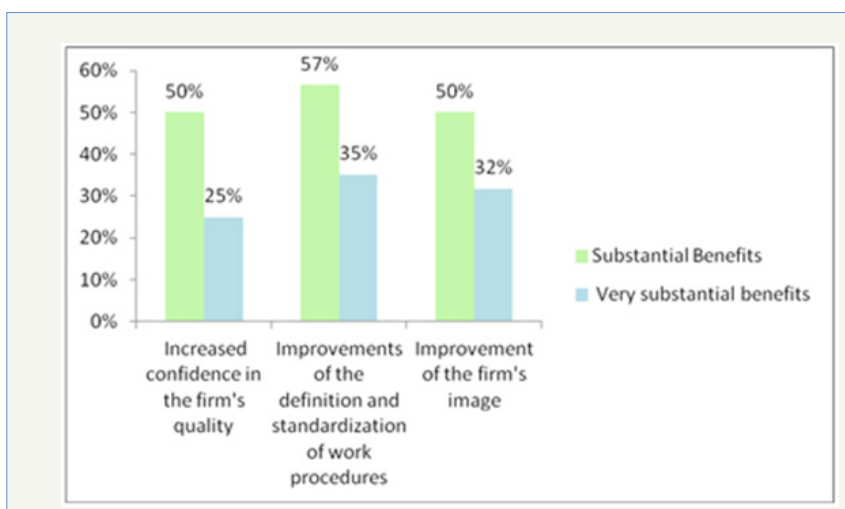

Figure 2: Benefits of quality system certification - substantial benefits/very substantial benefits (adapted from Oliveira [7]).

The majority of firms in our sample found that the main benefits of certification translated into increased confidence in the firms' quality; improvement of the definition and standardization 
of work procedures and improvement of the firm's image (Figure 2). One third of the firms in our sample agreed that competition is mainly by price and not by differentiation of product or service and that competition is extremely intense compared to other sectors (Figure 3).

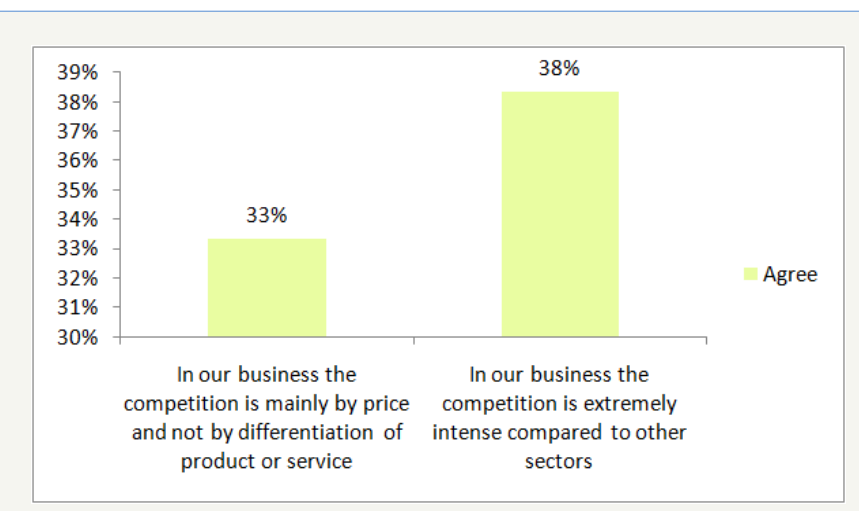

Figure 3: Competition-Agree (adapted from Oliveira [7]).

According Figure 4, firms do not feel that the demand in their business has been growing rapidly over the last 3 years. In particular, $80 \%$ of firms do not believe that in the past 3 years their business has been more profitable than other activities. $85 \%$ of firms felt that the fact that their activity is still in early growth is an important factor for competition.

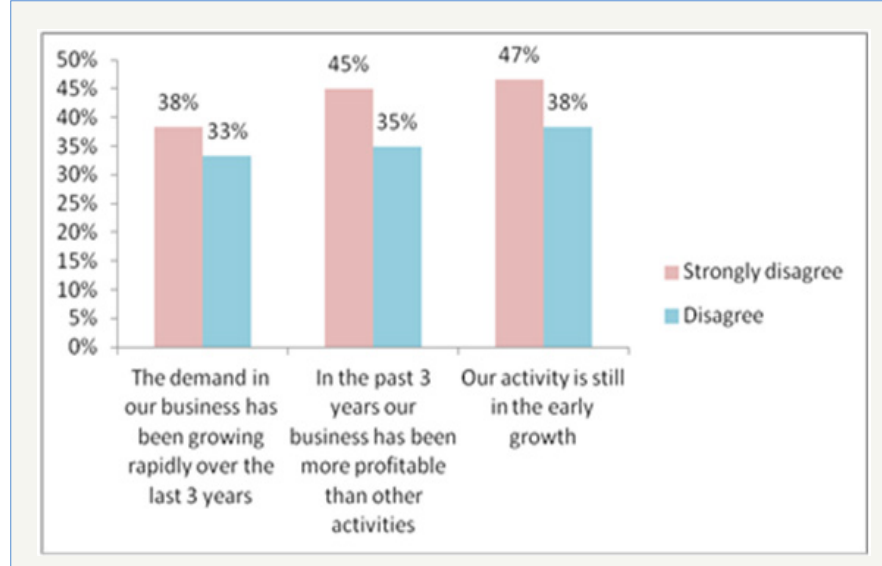

Figure 4: Competition strongly disagree/disagree (Adapted from Oliveira [7]).

On the other hand, most firms in our sample believe that quality improvement, business benefits, mobilizing employees' knowledge and business image were important or extremely important factors to implement quality system according ISO 9001 and achieve the certification (Figure 5). Benefits obtained by other certified firms, improved relations with authorities and the community were generally identified as unimportant reasons to implement the quality system by roughly one-third of the firms in our sample.

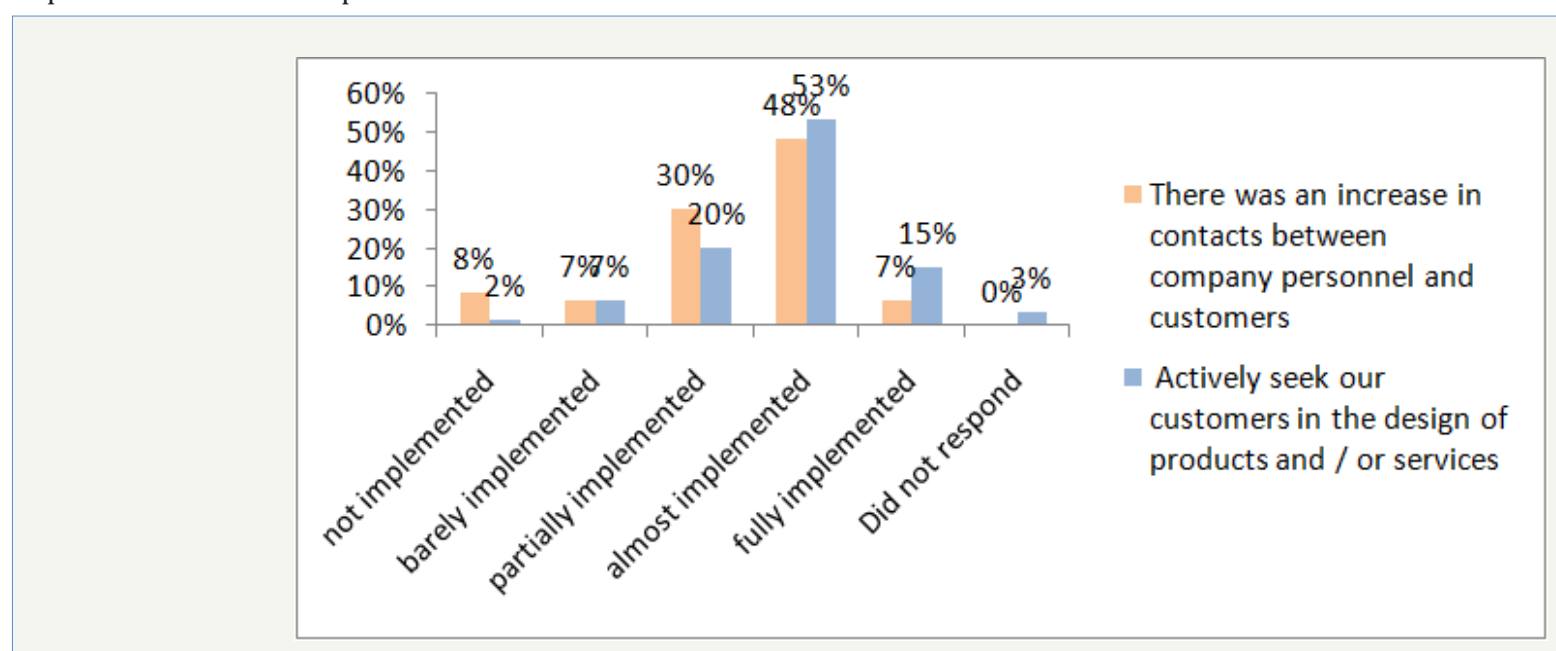

Figure 5: Implication for customers (Adapted from Oliveira [7])

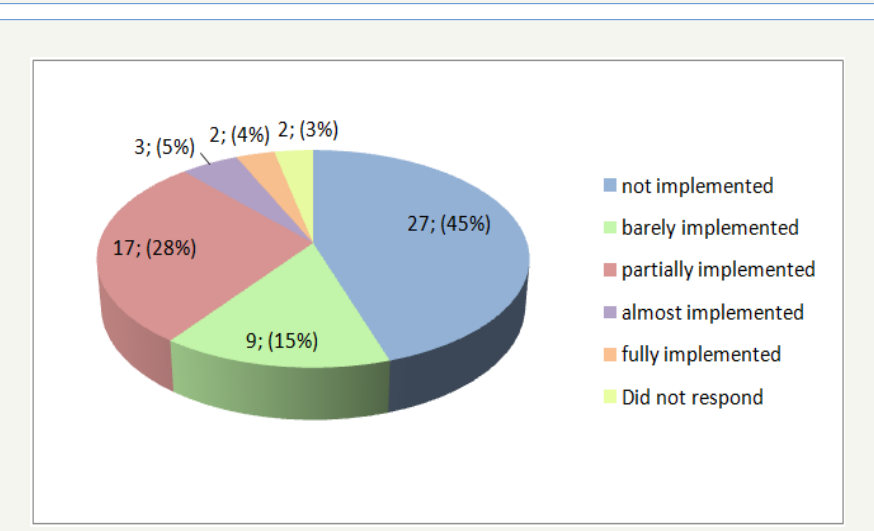

Figure 6: Benchmarking (Adapted from Oliveira [7]).
Close to $50 \%$ of the firms have not implemented the internal program of competitive benchmarking, while approximately $25 \%$ of the firms have partially implemented it and about $12,5 \%$ as barely implemented it (Figure 6). Few firms in our sample had almost or fully implemented the certification process. Some of the firms did not respond to some of the questions.

We found that $40 \%$ of the firms had partially implemented a very active system of employee suggestions and half of the firms increased the autonomy of employees to make decisions (Figure 7). The majority of firms (81\%) increased the employee involvement in planning and design tasks.

The majority of firms (64\%) have a commitment to a goal of zero defects (Figure 8). About three quarters of the firms (73\%) 
have a program of continuous reduction of defects and failures partially and almost implemented.65\% of the firms has a plan partially and almost implemented to dramatically reduce the reprocessing.

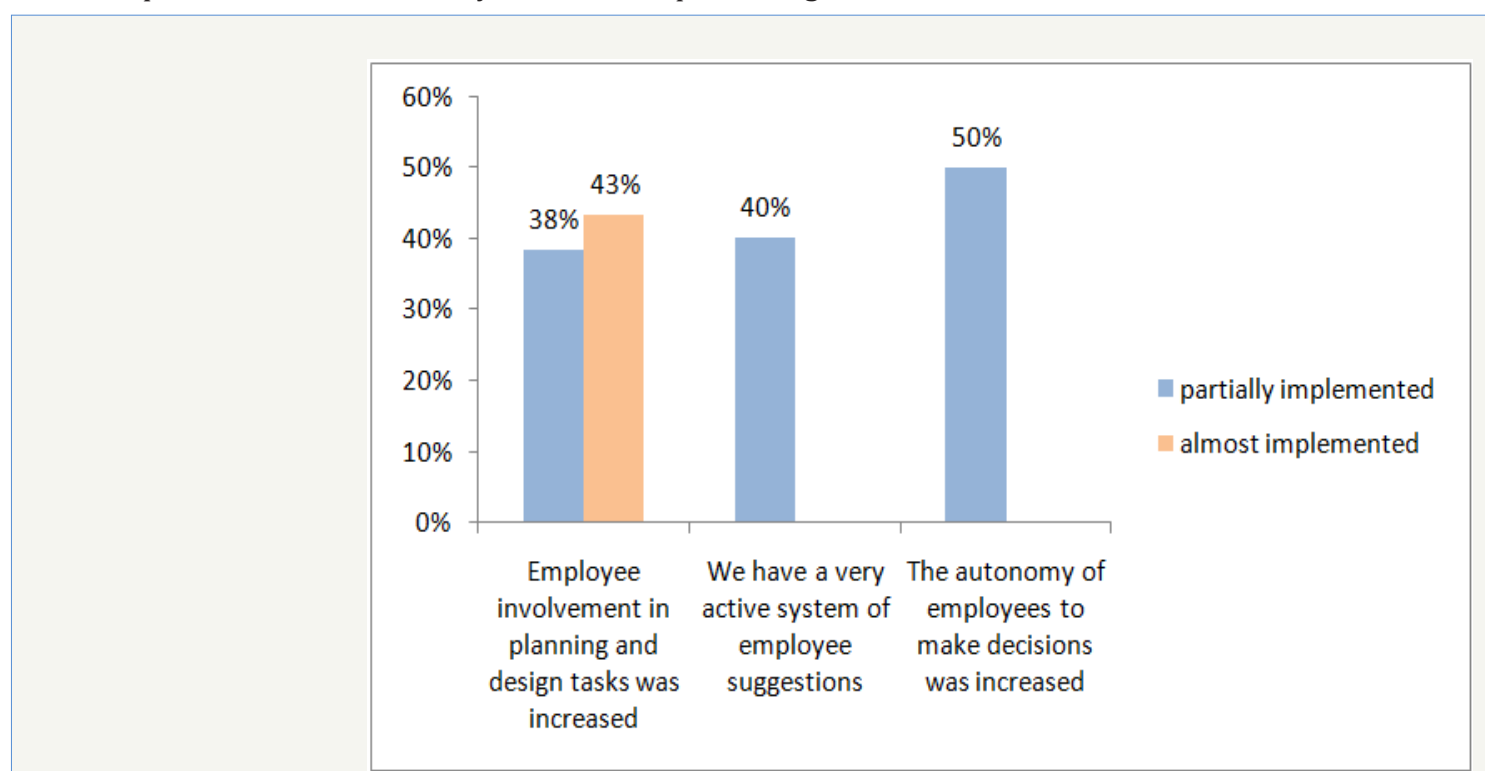

Figure 7: Empowerment (Adapted from Oliveira [7]).

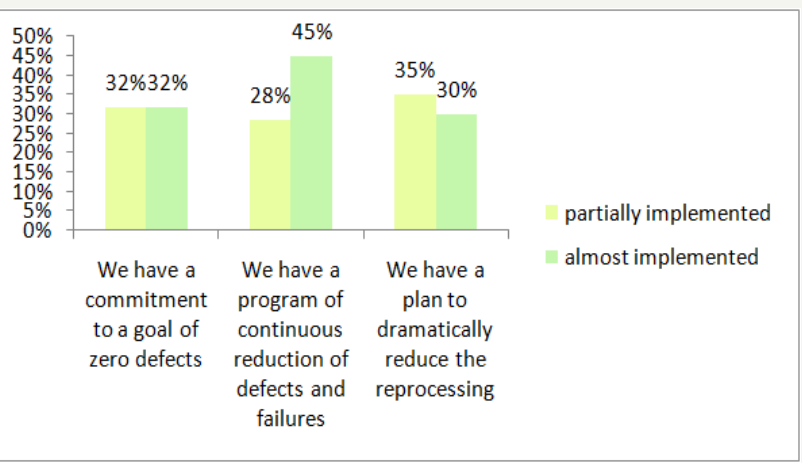

Figure 8: Zero defects mentality (Adapted from Oliveira [7]).

Finally, we asked that all firms to provide the main reasons why they undertook TQM measures. In particular, we asked each one to divide 100 points among 24 attributes based on their importance. With their responses, we constructed Table 2, which includes the attribute switch received the highest rankings. The majority of the firms in our sample undertake TQM measures for quality purposes to meet customer expectations and prevent errors (Table 2).

Table 2: Attributes which received the highest rankings (Adapted from [7]).

\begin{tabular}{|c|c|}
\hline 1 & Meet customer expectations \\
\hline 2 & Prevent errors \\
\hline 3 & Reduce costs by failures / malfunctions / waste \\
\hline 4 & Inspect and detect errors \\
\hline 5 & Respond quickly and appropriately to customer complaints \\
\hline 6 & Improve current levels of performance \\
\hline 7 & Projecting correctly from the beginning \\
\hline 8 & Surprise and delight the customer \\
\hline 9 & $\begin{array}{c}\text { To focus on the management of suppliers and customers as well } \\
\text { as in processes }\end{array}$ \\
\hline
\end{tabular}

\begin{tabular}{|l|c|}
\hline 10 & Reduce customer dissatisfaction \\
\hline 11 & To focus on "process" and the causes of errors \\
\hline 12 & Anticipate customer expectations \\
\hline 13 & Correct errors \\
\hline 14 & To focus on Client's "needs" \\
\hline 15 & To focus on "production" (products) \\
\hline 16 & Avoid inconvenience to customers \\
\hline 18 & Create new alternatives of doing things \\
\hline 19 & To focus on Customer's "preferences" \\
\hline 20 & "Create" customer preferences \\
\hline 21 & Review up on things well done \\
\hline 22 & Compensate customers beyond what they expected \\
\hline 23 & Obtain customer preferences in advance and follow them \\
\hline 24 & \\
\hline
\end{tabular}

\section{Results from interviews}

In the textile industry, the main reason for clients to seek other markets was price. In countries like Bangladesh, China, India and Vietnam, clients find that the prices to produce garments are lower as are the raw materials. On the other hand, these countries manage practice low prices because they are not concerned with environmental and social demands and so it can make them, incorrectly, more competitive. Another case is the salary paid to workers. Chinese can produce at a lower price, also, because salaries are much lower than Portuguese salaries are. According to Shapiro (2008), "the International Labour Organization and the Bureau of Labour Statistics of the USA, reported that an average worker in the manufacturing sector earns $\$ 23.65$ (US dollars) per hour in the USA, 24.63 dollars in France, and \$21.76 in Japan. It is compared with the \$6.38 in Taiwan, \$13.56 in South Korea and \$ 2.63 in Mexico". On the other hand, also in accordance with 
Shapiro (2008),"the manufacturing industry workers earn about 20 cents of the U.S. dollar per hour in China and 40 cents of the U.S. dollar per hour in India. Chinese and Indian workers employed in modern installations built by foreign firms earn more - like in Korea, Mexico and Thailand" [22]. In Portugal the average worker in manufacturing industry earns about $\$ 7$ per hour (in the textile industry is less). As such, for example the gains of French companies that move their production to Portugal may be about $351 \%$, but if he moves to China will be $12315 \%$.It is certain that the firms will have to pay the travel, but profits are still astronomical. Also according to Shapiro [22] "large differences in costs of labour in China and India, as compared with Taiwan and Mexico are the main reason that justifies that China, every year, claim hundreds of thousands of jobs to other developing countries".

On the other hand, Portuguese firms respect all trademarks of clients and products while Chinese devalue it. There is a massive and thriving black market in counterfeit designer apparel and accessories in countries such as China [5,7]. Due to this Chinamay practice low costs but also have more losses. As their garments do not have quality, clients return to their initial suppliers. Portuguese firms may have relocated their production to be cheaper but still fulfil all properties.

As prices in Portugal are higher, clients demand many quality tests in order to compensate the money that they paid. Some reasons that make clients come back to Portuguese textile firms are quality, punctuality, and creativity, when it comes to giving solutions and suggesting interesting new products.

The majority of the clients that once left Portugal did not come back. The few who came back were because the experience they had with other countries did not come out as they wished and the product was not as they were expecting too.

But the fact that the clients came back it does not necessary mean that it is good because their return rouse less stability, less loyalty, many demands in order to achieve the desired price. The ones that are still in Portugal were the ones that never left our country. The clients are here but the orders are fewer amounts and the types of garments too. They still continue in Portugal because they know that Portuguese firms accepts all types of orders when it concerns quantities. Orders with less quantities lead to higher costs with the management of processes, more errors and more technical human resources. Some new clients come to Portugal to visit Portuguese firms, to see how they work, what are their prices, their quality and to study their market.

Quality is very important because if Portugal did not bet on quality, the clients would never return. The lack of quality leads to the decrease of sales. That is one of the factors that make clients of Portuguese firms see that their product has quality and the sales are good because of that. During the time that the clients look for new markets, Portuguese firms took advantage of improving and optimizing their resources.

The clients are returning but as all know, the big orders are not coming back. Portuguese firms have to adapt and have a versatile structure to be prepared to receive them and to guarantee that their helpdesk is improved. Made in Portugal is a guarantee of quality unlike the image of the past. In order to survive the crises, the satisfaction of the final client is very important. Portuguese firms need to study very well all markets, need to know which products that the clients are looking for, need to be creative when it comes to the design of the garments, bet on innovation, be concerned with the product's image and its versatility.

If Portuguese firms take into account these factors, their space will guarantee. Without quality and without punctuality, clients seek for better conditions in other countries. Many firms in Portugal work for clients that represent very well known brands and quality is very important to assure that it creates more value, more margins, so that it justifies their stay. The work places are very important in a firm because they are responsible for quality. If they do not work properly, quality will not exist and neither will their work place. More and more, workers know it is like that. Workers have training in order to sensitize them with this issue; they receive information and are taught to deal correctly with the client's complaints, customer service, which are the firm's main goals and why the client is so important.

Clients like the loyalty felt by Portuguese firms because they like to create roots, feel well with the ones they work with and feel that it is not only because of the money. A very important aspect that happens in Portugal and does not happen with the majority of the countries is that Portuguese firms trust the clients based on the prestige and feedback collected initially and payments are made 30 to 60 days after the order is delivered. This does not happen in the other countries. They have to pay as they place the order.

Quality is an important tool that if it is used properly, it is a great weapon that Portuguese firms can use in their defence. The QMS well implemented is an instrument that can manage everything in a firm (human resources, behaviours), involving everybody with the firm, with the client and will the society. Workers are an important link in the firm's performance and if all perform their functions properly, this will be reflected throughout the firm.

\section{Discussion}

We undertook this analysis to evaluate the impact of quality on textile firms' survival northern Portugal. This region was chosen because the majority of the Portuguese textile industry is located there. Most firms in our sample felt that quality improvement, business benefits, mobilizing employees' knowledge and business image were important factors in implementing qualityrelated measures. Furthermore, we found that competition is very intense and is mainly driven by price and not by product/ service differentiation. The majority of firms undertook TQM measures to meet customer expectations and prevent errors. This is a general concern in, among all countries. We can state that Portuguese textile businessmen have a similar approach to those in the UK described by Middleton [4]. This approach is also shared by Spanish businessmen [23]. They consider quality to be an important tool to survive in textile market. However, they also believe that it is important to closely follow the market to increase 
their competitiveness. Despite this concern with quality, some UK firms have reduced their manufacturing capacity and transferred it to countries that offer cheaper labour, such as Eastern Europe, Africa and Asia. With lower costs, firms' profit margins will increase many thousands percent. Quality is very important because the lack of it would lead the clients of Portuguese firms never return to them. The lack of quality leads to the decrease of sales. It is very important to assure that it creates more value, more margins, so that it justifies their stay.

Although quality is the one of the most important aspects of the production process, there are other factors that clients consider important, such as, competitive prices, delivering orders on time, creativity, customer loyalty, and more recently, the environment, working conditions and social responsibility [24].

\section{Conclusion}

The textile industry in Portugal is going through many changes, which have a direct impact on a firm's level of competitiveness. We found that the quality plays an important role in a firm's survival. The results of our study suggest that the majority of the firms in our sample undertake TQM measures for quality purposes, to meet customer expectations and to prevent errors. Most firms chose to implement QMS because they felt that quality improvement, business benefits, mobilizing employees' knowledge and business image were important to increase competitiveness. They found that the main benefits of certification translated into increased confidence in the firms' quality; improvement of the definition and standardization of work procedures and improvement of the firm's image. Moreover, the majority of the firms stated that the implementation of quality programs led to higher profits and an improvement in the quality of their output [25]. Overall, the implantation of a quality program has improved their competitive position and their overall performance.

It can be concluded that Portuguese firms share similar views regarding quality-related interventions and its importance within the Portuguese textile sector. Findings of our study can help shed light on the current situation of the Portuguese textile sector and how the implementation of quality related measures and the demand, by major brands, for new markets to produce their products, can impact the textile industry in other regions.

\section{References}

1. Bergvall FJ, Towers N (2007) Creating agile supply networks in the fashion industry: A pilot study of the European textile and clothing industry. The Journal of the Textile Institute 98(4): 377-385.

2. Frederick S, Cassill N (2009) Industry clusters and global value chains: analytical frameworks to study the new world of textiles. The Journal of the Textile Institute 100(8): 668-681.

3. Towers N, McLaughlin J (2005) Effective total quality management in the textile fashion retail supply chain: A pilot survey of the UK textile manufacturers. The Journal of the Textile Institute 96(2): 87-92.

4. Middleton D (2004) The business process revolution in UK textile manufacturing. Journal of the Textile Institute 95(1-6): 1-7.

5. Visão (2012) Magazine.

6. Santos G, Mandado E (2016) Technological differences between north and southern european countries. Communication presented at " $19^{\text {th }}$ QMOD-International conference on quality and service sciences". Roma Tre University, Italy.

7. Oliveira S (2013) The importance of quality in the consolidation of textile firms in minho. Master Thesis, Polytechnic Institute Cavado Ave, Barcelos, Portugal.

8. Santos G, Pais MS, Pereira AL, Machado VC (1996) Impact of quality certification in SMEs. Communication presented at " $40^{\text {th }}$ Congress" of "European Organization for Quality". Berlin, Germany.

9. Félix MJ (2009) Contribution for a strategic vision on design research in Portugal.

10. Dadashian F, Monfared MAS, Nasrabadi HG (2009) Design of a new quality assessment system for textile products. The Journal of the Textile Institute 100(7): 640-648.

11. Powell NB, Cassill NL (2006) New textile product development: processes, practices, and products. The Journal of the Textile Institute 97(2): 155-166.

12. Santos G, Soto E, Félix MJ, Mandato E (2017) Philosophy of technology and its application to mechanics and materials in design. In: Silva Gomes JF, Meguid SA (Eds.), Proceedings of the $7^{\text {th }}$ international conference on mechanics and materials in design. Albufeira/Portugal.

13. Vasconcelos E (2006) Analysis of the textile and clothing industry. Consultoria empresarial, Lda, Minho's university, Portugal.

14. Sousa CMT (2009) Energy recovery of textile and polymeric industrial wastes. Minho's university, Portugal.

15. Pina JAT, Sellés SME (2008) Management and Measurement of quality in ISO 9000 organizations: An empirical study in Spain. Total Quality Management \& Business Excellence 19(5): 481-492.

16. Rebelo M, Santos G, Silva R (2013) Conception of a flexible integrator and lean model for integrated management systems. Total Quality Management \& Business Excellence 25(5-6): 683-701.

17. Dahlgaard Park SM, Chen CK, Jang JY, Dahlgaard JJ (2013) Diagnosing and prognosticating the quality movement a review on the 25 years quality literature (1987-2011). Total Quality Management \& Business Excellence 24(1-2): 1-18.

18. Dereli T, Durmuşoğlu A, Delibaş D, Avlanmaz N (2011) An analysis of the papers published in total quality management \& business excellence from 1995 through 2008. Total Quality Management \& Business Excellence 22(3): 373-386.

19. Arauz R, Suzuki H (2004) ISO 9000 Performance in Japanese Industries. Total Quality Management \& Business Excellence 15(1): 3-33.

20. Santos G, Milán AL (2013) Motivation and benefits of implementation and certification according ISO 9001-The Portuguese experience. International Journal for Quality Research 7(1): 71-86.

21. Lambert G, Ouedraogo N (2008) Empirical investigation of ISO 9001 quality management systems' impact on organizational learning and process performances. Total Quality Management \& Business Excellence 19(10): 1071-1085.

22. Shapiro RJ (2008) Futurecaste . Portuguese version. Actual editora, Lisbon.

23. De Cerio JMD (2003) Factors relating to the adoption of quality management practices: An analysis for Spanish manufacturing firms. Total Quality Management \& Business Excellence 14(1): 25-44.

24. Batista I, Santos G (2015) The financial impact of quality audits in portuguese companies. Production and Development Magazine 1(3): 90-102.

25. Costa J (2008) Quality Management Systems in Portuguese Companies: Implantation, Impact and Performance. Doctoral Thesis, University of Seville, Spain. 
Creative Commons Attribution 4.0

International License

For possible submissions click Here

\section{Submit Article}

Creative Commons Attribution 4.0

International License

For possible submissions click Here
Your subsequent submission with Crimson Publishers will attain the below benefits

- High-level peer review and editorial services

- Freely accessible online immediately upon publication

Your subsequent submission with Crimson Publishers will attain the below benefits

- High-level peer review and editorial services

- Freely accessible online immediately upon publication

- Authors retain the copyright to their work

- Licensing it under a Creative Commons license

- Visibility through different online platforms

- Global attainment for your research

- Article availability in different formats (Pdf, E-pub, Full Text)

- Endless customer service

- Reasonable Membership services

- Reprints availability upon request

- One step article tracking system 